\title{
Clinical Implications of Subclinical Hypothyroidism in Continuous Ambulatory Peritoneal Dialysis Patients
}

\author{
Ea Wha Kang ${ }^{\text {a Ju Young Nam }}{ }^{b}$ Tae-Hyun Yoo ${ }^{a}$ Sug Kyun Shin ${ }^{a}$ \\ Shin-Wook Kang ${ }^{c}$ Dae-Suk Han ${ }^{c}$ Seung Hyeok Han ${ }^{c}$ \\ Divisions of a Nephrology and ${ }^{b}$ Endocrinology, Department of Internal Medicine, NHIC Ilsan Hospital, Koyang, \\ Kyungki-do, and ${ }^{\mathrm{C}}$ Department of Internal Medicine, Yonsei University College of Medicine, Seoul, Korea
}

\section{Key Words \\ Subclinical hypothyroidism - Continuous ambulatory peritoneal dialysis • Left ventricular dysfunction}

\begin{abstract}
Background: Despite the high prevalence of subclinical hypothyroidism in patients with chronic kidney disease, little is known about the clinical features and implications of this disorder in end-stage renal disease patients. This study aimed to investigate the clinical implications of subclinical hypothyroidism in continuous ambulatory peritoneal dialysis (CAPD) patients. Methods: This is a cross-sectional study with 51 stable patients who were maintained on CAPD for more than 3 months. A thyroid function test with blood sampling and echocardiography were conducted. Subclinical hypothyroidism was defined as a thyrotropin (TSH) level over $5 \mathrm{mIU} / \mathrm{l}$ and normal free $\mathrm{T}_{4}$. Results: Of the 51 patients, subclinical hypothyroidism was detected in 14 (27.5\%). Among those with subclinical hypothyroidism, only 4 (28.6\%) patients had autoimmune thyroiditis. Patients with subclinical hypothyroidism had lower left ventricular ejection fractions (LVEF; 61.5 vs. $70.0 \%, p=0.002$ ) and lower fractional shortening at endocardial levels (endoFS; 33.9 vs. $40.0 \%, p=$ 0.009) compared to those with normal TSH levels. In addition, logTSH was inversely associated with LVEF ( $r=-0.361$,
\end{abstract}

$p=0.009)$ and endoFS $(r=-0.320, p=0.022)$. In a multivariate linear regression, adjusted for age, diabetes, previous coronary artery disease and logCRP (C-reactive protein), $\log$ TSH was an independent correlate with LVEF $(\beta=-0.388$, $p<0.001)$. Conclusion: This study suggests that subclinical hypothyroidism is common and might be implicated in cardiac dysfunction in CAPD patients.

Copyright $\odot 2008$ S. Karger AG, Basel

\section{Introduction}

End-stage renal disease (ESRD) is a frequent cause of alterations in thyroid hormones without any underlying intrinsic thyroid disorder. A variety of alterations in thyroid hormone levels and/or metabolism have been described in patients with chronic kidney disease (CKD) [1, 2]. Serum triiodothyronine $\left(\mathrm{T}_{3}\right)$ levels are frequently low in dialysis patients, which reflect a diminished conversion of $\mathrm{T}_{4}$ (thyroxine) to $\mathrm{T}_{3}$ in the periphery. This abnormality is not associated with an increased conversion of $\mathrm{T}_{4}$ to the metabolically inactive reverse $\mathrm{T}_{3}\left(\mathrm{rT}_{3}\right)$, since se-

The results presented in this paper have not been published previously in whole or part, except in abstract form.

\section{KARGER}

Fax +41613061234

E-Mail karger@karger.ch

www.karger.com (c) 2008 S. Karger AG, Basel

0250-8095/08/0286-0908\$24.50/0

Accessible online at:

www.karger.com/ajn
Seung Hyeok Han, MD

Department of Internal Medicine, Yonsei University College of Medicine

Seoul 120-752 (Korea)

Tel. +82 22228 5346, Fax +82 23647655

E-Mail anythingbox70@gmail.com 
rum $\mathrm{rT}_{3}$ levels are typically normal. This finding differentiates uremic patients from those with chronic illness, who are characterized by increased $\mathrm{rT}_{3}$ [3] .

Subclinical hypothyroidism is biochemically defined as a high serum thyrotropin (TSH) concentration and normal serum free thyroxine $\left(\mathrm{fT}_{4}\right)$ and $\mathrm{T}_{3}$ concentrations [4]. It occurs in $5-15 \%$ of the general population, and the risk of developing subclinical hypothyroidism increases with female gender, advanced age and greater dietary iodine intake [5]. Depressed left ventricular (LV) systolic function and LV hypertrophy are well-recognized features of subclinical hypothyroidism, and the causal role of thyroid hormone deficiency in cardiomyopathy is indicated by the observation that these alterations revert to normal during L-thyroxine treatment [6]. Also, subclinical hypothyroidism may be associated with increased risks of cardiovascular disease and, possibly, all-cause mortality [7]. In ESRD patients, cardiovascular complications represent the major cause of mortality, and LV systolic dysfunction and LV hypertrophy are powerful predictors of death [8]. In addition, it has been suggested that primary hypothyroidism is more common in this population compared to the general population $[1,2]$. However, little is known about the clinical features and implications of subclinical hypothyroidism in patients with ESRD. Therefore, we undertook a cross-sectional study to investigate the clinical implications of subclinical hypothyroidism in continuous ambulatory peritoneal dialysis (CAPD) patients.

\section{Patients and Methods}

\section{Study Population}

Out of the 82 prevalent CAPD patients, those who had been on CAPD for less than 3 months and had intercurrent acute illness were excluded. In addition, patients who had previous intrinsic thyroid diseases or were taking drugs known to interfere with thyroid function (i.e. corticosteroids, amiodarone, rifampin, lithium, $\beta$-blockers) were excluded. As a result, 51 patients were included in the final analysis.

Patients were treated with 3 or 4 two-liter exchanges per day, using standard dialysates containing glucose. Dialysis prescription aimed at obtaining a total $\mathrm{Kt} / \mathrm{V}$ of at least 1.7 per week.

\section{Echocardiography}

All echocardiograms were made with an empty abdomen. Left ventricular mass was calculated according to the recommended formula of the American Society of Echocardiography: LV mass $=0.8\left\{1.04 \times\left[(\text { LVIDd }+ \text { PWTd }+ \text { SWTd })^{3}-(\text { LVIDd })^{3}\right]\right\} \times$ $0.6 \mathrm{~g}$ and indexed to the body surface area [LV mass index (LVMI), $\mathrm{g} / \mathrm{m}^{2}$ ], where LVIDd, PWTd and SWTd are LV internal dimensions at end diastole, posterior wall thickness at end diastole and septal wall thickness at end diastole, respectively [9]. Left ventricular hypertrophy was defined by a LVMI $>100 \mathrm{~g} / \mathrm{m}^{2}$ in women or $>120 \mathrm{~g} / \mathrm{m}^{2}$ in men. Left ventricular ejection fraction (LVEF) was calculated by the $2 \mathrm{D}$ method [10]. Fractional shortening at endocardial levels (endoFS) was calculated by the formula: endoFS $=($ LVEDD - LVESD $) /$ LVEDD $\times 100$, where LVEDD and LVESD represent the diameter of the left ventricle at end diastole and end systole, respectively). A LVEF $<50 \%$ or a endoFS $<28 \%$ was indicative of LV systolic dysfunction [10].

In addition, the peak early (E; meters per second) and late (A; meters per second) mitral inflow velocities were measured. With these values, E/A ratios were determined, and diastolic dysfunction was defined as an $\mathrm{E} / \mathrm{A}$ ratio $<1.0$.

\section{Laboratory Measurements}

Serum lipids, albumin, hemoglobin, calcium, phosphate, and C-reactive protein (CRP) were measured by standard methods. Serum $\mathrm{T}_{3}(60-181 \mathrm{ng} / \mathrm{dl}), \mathrm{fT}_{4}(0.6-1.5 \mathrm{ng} / \mathrm{dl})$ and TSH $(0.35-4.94$ $\mathrm{mIU} / \mathrm{l})$ were determined by chemiluminescent immunoassay (Hitachi, Tokyo, Japan). Thyroid autoantibody tests (thyroid microsomal $\mathrm{Ab}$ and thyroglobulin $\mathrm{Ab}$ ) were performed by the same method. Subclinical hypothyroidism was defined when the TSH level was over $5 \mathrm{mIU} / \mathrm{l}$ with normal $\mathrm{fT}_{4}$, and overt hypothyroidism was defined when the TSH level was over $5 \mathrm{mIU} / \mathrm{l}$ with decreased fT4 [4].

Patients were divided into two groups according to TSH levels (normal vs. $\geq 5 \mathrm{mIU} / \mathrm{l}$ ). Demographic, clinical and laboratory parameters and echocardiographic findings were compared between the two groups.

\section{Statistical Analysis}

The statistical analysis was performed using SPSS version 11.0 (SPSS, Chicago, Ill., USA). All data were expressed as medians with ranges. Data which showed skewed distributions, such as CRP and TSH, were expressed as log transformations. The comparisons between the two groups were made by Student's t test and $\chi^{2}$ tests. Relationships between paired parameters were analyzed by Pearson correlation coefficients. The independent association between serum TSH and LV systolic function expressed as LVEF (as a percentage) was analyzed further by multiple linear regression analysis adjusting for other factors with a p value of less than 0.10 on univariate analysis. The level of significance was set at 0.05 .

\section{Results}

\section{Patient Characteristics}

Table 1 details characteristics of the 51 patients. The median age of the subjects was 63 years and $51 \%$ were male. Diabetes was the most common cause of ESRD (49.0\%) and 19 patients (37.3\%) had previous coronary artery occlusive diseases (CAOD). The median $\mathrm{T}_{3}$ and TSH levels were $98 \mathrm{ng} / \mathrm{dl}$ and $2.9 \mathrm{mIU} / \mathrm{l}$, respectively. Subclinical hypothyroidism was detected in $14(27.5 \%)$ patients. Only 4 patients (28.6\%) among those with subclinical hypothyroidism were identified as having autoim- 
Table 1. Patient characteristics $(n=51)$

$\begin{array}{lc}\text { Age, years } & 63(35-85) \\ \text { Gender (male/female), } \mathrm{n} & 26 / 25 \\ \text { Diabetes, } \mathrm{n} & 25(49.0 \%) \\ \text { CAPD duration, months } & 8(3-62) \\ \text { CAOD, n } & 19(39.3 \%) \\ \mathrm{BMI} & 24.3(17.7-29.6) \\ \text { Weekly Kt/V urea } & 2.4(1.72-4.06) \\ \text { Residual GFR, ml/min/1.73 m }{ }^{2} & 4.5(0-15.9) \\ \text { Serum albumin, g/dl } & 3.5(2.1-4.3) \\ \text { CRP, mg/dl } & 0.09(0.01-1.34) \\ \text { Hemoglobin, g/dl } & 10.7(7.2-13.1) \\ \text { Total cholesterol, mg/dl } & 179(113-273) \\ \text { Triglyceride, mg/dl } & 154.5(44-428) \\ \mathrm{T}_{3}, \text { ng/dl } & 98(67-162) \\ \mathrm{fT}_{4}, \text { ng/dl } & 1.00(0.9-1.5) \\ \text { TSH, mIU/l } & 2.93(0.5-26.8) \\ \text { Subclinical hypothyroidism, } \mathrm{n} & 14(27.5 \%) \\ \text { Echocardiographic findings } & \\ \quad \text { LVEF, \% } & 67(40-80) \\ \quad \text { endoFS, \% } & 38.3(21.1-68.6) \\ \quad \text { LVMI, g/m } & \\ \quad \text { E/A ratio } & 120(74-160) \\ \end{array}$

mune thyroiditis. There was no patient with overt hypothyroidism.

\section{Comparison between Patients with Subclinical}

Hypothyroidism and Those with Normal TSH Levels

When patients were divided into the two groups on the basis of TSH concentrations, there were no significant differences in the proportions of diabetes, previous CAOD, serum albumin, serum CRP and the lipid profile between the two groups. In addition, weekly Kt/V urea, residual glomerular filtration rate (GFR) and CAPD duration were not different between groups. However, patients with subclinical hypothyroidism were significantly older compared with those with normal TSH levels (58 vs. 68 years old, $\mathrm{p}<0.01$ ). Echocardiographic findings revealed that patients with subclinical hypothyroidism had lower LVEF (62 vs. 70\%, $\mathrm{p}=0.002$ ) and lower endoFS levels ( 33.9 vs. $40.0 \%, p=0.009)$ compared to those with normal TSH levels. The LVMI and E/A ratio were not different between the groups (table 2).

\section{Factors Related to TSH Levels and LV Systolic \\ Function}

Bivariate correlation analyses revealed that $\log \mathrm{TSH}$ was inversely associated with $\operatorname{LVEF}(r=-0.361, p=0.009)$, endoFs $(r=-0.320, p=0.022)$ and age $(r=0.315, p=$
Table 2. Comparison between patients with subclinical hypothyroidism and those with normal TSH levels

\begin{tabular}{lcc}
\hline & $\begin{array}{l}\text { Normal TSH } \\
(\mathrm{n}=37)\end{array}$ & $\begin{array}{l}\text { TSH } \geq 5 \mathrm{mIU} / \mathrm{l} \\
(\mathrm{n}=14)\end{array}$ \\
\hline Age, years & $58(35-83)$ & $68(55-85)^{* *}$ \\
Gender (male/female), $\mathrm{n}$ & $21 / 16$ & $5 / 9$ \\
Diabetes, $\mathrm{n}$ & $19(51.4 \%)$ & $6(42.9 \%)$ \\
CAPD duration, months & $8(3-62)$ & $8(3-17)$ \\
CAOD, n & $12(32.4 \%)$ & $7(50.0 \%)$ \\
BMI & $23.7(17.7-29.6)$ & $25.5(20.6-28.4)$ \\
Weekly Kt/V urea & $2.4(1.7-4.1)$ & $2.4(1.7-3.6)$ \\
Residual GFR, & & \\
$\quad$ ml/min/1.73 m ${ }^{2}$ & $4.8(0-15.9)$ & $4.5(1.4-9.5)$ \\
Serum albumin, g/dl & $3.4(2.1-4.1)$ & $3.6(3.1-4.3)^{*}$ \\
CRP, mg/dl & $0.06(0.01-1.34)$ & $0.15(0.02-0.63)$ \\
Hemoglobin, g/dl & $10.4(7.2-12.3)$ & $11.2(8.0-13.1)$ \\
Total cholesterol, mg/dl & $178(113-273)$ & $179(140-241)$ \\
Triglyceride, mg/dl & $147(44-428)$ & $183(82-398)$ \\
$\mathrm{T}_{3}$, ng/dl & $97.0(67-162)$ & $101.5(75-138)$ \\
fT $_{4}$, ng/dl & $1.0(0.8-1.5)$ & $1.0(0.8-1.4)$ \\
TSH, mIU/l & $2.45(0.52-4.41)$ & $7.03(5.08-26.8)^{* *}$ \\
Echocardiographic findings & & \\
$\quad$ LVEF, \% & $70(46-80)$ & $61.5(40-70)^{* *}$ \\
$\quad$ endoFS, \% & $40.0(26.4-68.6)$ & $33.9(21.1-45.0)^{*}$ \\
$\quad$ LVMI, g/m ${ }^{2}$ & $120(74-160)$ & $130(95-140)$ \\
$\quad$ E/A ratio & $0.66(0.21-2.93)$ & $0.73(0.56-1.80)$ \\
\hline
\end{tabular}

${ }^{*} \mathrm{p}<0.05,{ }^{* *} \mathrm{p}<0.01$ vs. normal TSH group.

0.026). However, there was no significant correlation between $\log$ TSH and $\log$ CRP (fig. 1). Multivariate linear regression analyses showed that only $\operatorname{LVEF}(\beta=-0.493$, $\mathrm{p}=0.007)$ was identified as a significant correlate with $\log \mathrm{TSH}$, adjusting for age, diabetes, serum albumin, previous CAOD and $\log \mathrm{CRP}$ (table 3 ).

In addition, $\log \mathrm{TSH}(\beta=-0.388, \mathrm{p}=0.006), \log \mathrm{CRP}$ $(\beta=-0.334, p=0.036)$ and previous CAOD $(\beta=-0.330$, $\mathrm{p}=0.031$ ) were independently associated with LVEF on the multivariate analysis adjusted for age, diabetes, serum albumin, $\log \mathrm{CR}$, previous CAOD and $\log \mathrm{TSH}$ (table 3).

\section{Discussion}

In the United States, the National Health and Examination Survey (NHANES III) reported that $4.3 \%$ of 16,533 people had subclinical hypothyroidism [11]. In that study, chronic autoimmune thyroiditis was found in $54 \%$ of patients with subclinical hypothyroidism. Similarly, a re- 
Fig. 1. Factors related to TSH. $\operatorname{LVEF}(\mathbf{a} ; \mathbf{r}=$ $-0.361, p=0.009)$, endoFS (b; $r=-0.320$, $\mathrm{p}=0.022)$ and age $(\mathbf{c} ; \mathrm{r}=0.315, \mathrm{p}=0.026)$ were inversely associated with logTSH. However, $\log \mathrm{CRP}$ was not significantly associated with $\log \mathrm{TSH}(\mathbf{d} ; \mathrm{r}=0.135, \mathrm{p}=$ 0.345).

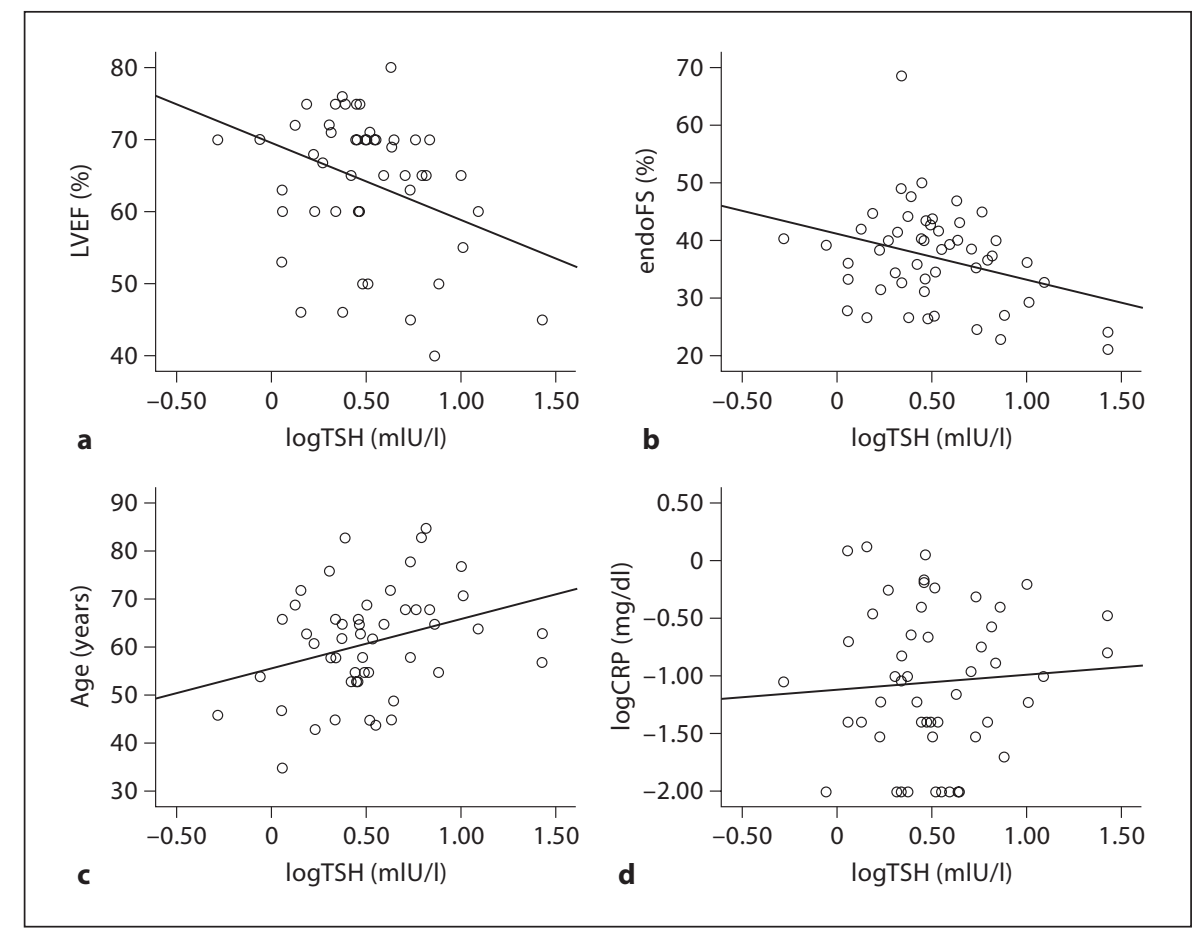

Table 3. Multivariate linear regression for TSH and LVEF

\begin{tabular}{|c|c|c|c|c|}
\hline & \multicolumn{2}{|c|}{$\log \mathrm{TSH}$} & \multicolumn{2}{|c|}{ LVEF (\%) } \\
\hline & $\beta$ & $\mathrm{p}$ value & $\beta$ & $\mathrm{p}$ value \\
\hline Age & 0.273 & 0.162 & 0.246 & 0.153 \\
\hline Diabetes & 0.008 & 0.961 & 0.041 & 0.768 \\
\hline Serum albumin & 0.001 & 0.999 & -0.038 & 0.790 \\
\hline $\log \mathrm{TSH}$ & - & - & -0.361 & 0.008 \\
\hline $\log C R P$ & -0.207 & 0.235 & -0.378 & 0.011 \\
\hline Previous CAOD & -0.062 & 0.709 & -0.370 & 0.008 \\
\hline $\mathrm{LVEF}^{1}$ & -0.462 & 0.008 & - & - \\
\hline
\end{tabular}

${ }^{1}$ Adjusted for age, diabetes, serum albumin, $\log \mathrm{TSH}, \log \mathrm{CRP}$ and previous CAOD.

port from the UK showed that $67 \%$ of females and $40 \%$ of males with subclinical hypothyroidism had high serum antithyroid antibody concentrations [12]. Lo et al. [13] examined the prevalence of hypothyroidism in CKD patients using data from NHANES III, and they found an increased prevalence of hypothyroidism in patients with reduced GFR. In addition, with progressively lower GFR, there was a graded and increased likelihood of hypothyroidism. Furthermore, elevated levels of thyroid peroxi- dase antibodies were less frequently observed at lower GFR. In line with the previous report of Kaptein et al. [1], our cross-sectional study showed that subclinical hypothyroidism was common (27.5\%) in CAPD patients. Interestingly, most subclinical hypothyroidism in our study was non-autoimmune thyroiditis (78.8\%), which was similar to the findings of Lo et al. [13]. Recently, Zoccali et al. [22] reported subclinical hypothyroidism in CAPD patients. However, study subjects in their study only presented low $\mathrm{fT}_{3}$ without elevated TSH; therefore, no subclinical hypothyroidism was evaluated. They appear to be closer to low $\mathrm{T}_{3}$ syndrome, which is clearly different from subclinical hypothyroidism. By definition, subclinical hypothyroidism is considered as a high serum TSH concentration and normal serum $\mathrm{fT}_{4}$ and $\mathrm{T}_{3}$ concentrations [4]. In contrast, we focused on CAPD patients with elevated TSH levels.

The reason for the elevated TSH levels in CAPD patients was not clear. Iodide excess due to reduced renal excretion may contribute to the increased frequency of hypothyroidism in ESRD patients [14]. Sato et al. [15] reported that hypothyroidism was reversed after dietary iodine restriction in $83 \%$ of 245 Japanese patients with mild to severe renal dysfunction and elevated nonhormonal iodine levels. These patients were characterized by thyroidal iodide organification defects [15]. Another pos- 
sible reason for the increased frequency of hypothyroidism in CAPD patients was thyroid hormone losses via peritoneal fluid. However, this explanation was contradicted by a report from Robey et al. [16], indicating that none of the patients were overtly hypothyroid because $\mathrm{T}_{4}$ and $\mathrm{T}_{3}$ losses were relatively modest and remained below their daily production rates despite the finding that large amounts of protein are lost in peritoneal fluid [16]. Also, serum TSH levels were mildly elevated in 3 of 9 patients, which was consistent with subclinical hypothyroidism. Our study clearly showed that there were no differences in weekly Kt/V urea, residual GFR and CAPD duration between patients with subclinical hypothyroidism and those with normal TSH levels. This finding implies that elevated TSH levels in patients with subclinical hypothyroidism were not simply explained by clearance difference. CKD or ESRD per se may be associated with increased TSH or reduced thyroid function, in which retained solutes such as organic acids and uremic toxic compounds might play a role.

The present study revealed that CAPD patients with subclinical hypothyroidism had lower LV systolic function compared to those with normal TSH levels, and elevated TSH levels were independently associated with decreased LVEF. A number of sources reported that subclinical hypothyroidism is associated with an increased risk of cardiovascular disease, and, possibly, all-cause mortality [7]. In addition, an impairment in LV function in subclinical hypothyroidism was often recovered by $\mathrm{T}_{4}$ replacement therapy $[17,18]$. Although the exact mechanism of LV dysfunction in subclinical hypothyroidism still remains to be further clarified, our study suggests that subclinical hypothyroidism might be implicated in LV dysfunction in CAPD patients, in a similar way as the general population. Another of the key cardiac manifestations in subclinical hypothyroidism is LV diastolic dysfunction [19], which is characterized by impaired early ventricular filling on echocardiography. Often, this is associated with a variable impairment in LV systolic function at rest $[17,19]$. Our study showed that there were no significant differences in the E/A ratios between patients with subclinical hypothyroidism and those with normal TSH levels, although it was slightly lower in the former $(p=0.087)$. The reason for this finding is uncertain; however, it can be presumed that, independent of thyroid abnormality, preexisting impaired diastolic function in uremic patients [20] might result in similar E/A ratios between the 2 groups.

Recently, low $\mathrm{fT}_{3}$ was reported to be implicated in the adverse cardiac effects of inflammation in patients with
ESRD $[21,22]$. In line with these findings, our study revealed that serum $\mathrm{T}_{3}$ levels were inversely correlated with $\log \mathrm{CRP}(\mathrm{r}=-0.325, \mathrm{p}=0.020$, data not shown). Although mechanisms whereby inflammation perturbs thyroid function are still poorly defined, the prevailing view is that nonthyroidal illness is an acute-phase response generated by activation of the cytokine network [23]. However, we could not find a significant relationship of $\mathrm{T}_{3}$ levels with a decreased $\operatorname{LVEF}(\mathrm{r}=0.057, \mathrm{p}=0.691$, data not shown), which is not consistent with Zoccali et al. [24]. This discrepancy could be partly explained by the lower proportion of patients with low $\mathrm{T}_{3}$ levels, the shorter dialysis duration ( 9 vs. 43 months) of our subjects and different dialysis modalities provided between the 2 studies, which might lead to a difference in microinflammation. Actually, serum CRP levels in our subjects were much lower than those in their subjects, although clear comparisons could not be made.

There are several limitations to this study. First, this is a cross-sectional study with a small sample size. As a cross-sectional study design, all data were collected at a single time, which might not yield a precise patient status. Hence, the causality of our findings needs further confirmation. The small sample size is another drawback that might lead to selection bias. Despite these limitations, it should be noted that subclinical hypothyroidism was significantly associated with LV systolic dysfunction in this study. To our knowledge, there has been no report about the relationship between subclinical hypothyroidism and LV systolic dysfunction in CAPD patients.

In conclusion, our study showed that subclinical hypothyroidism was prevalent and autoimmune thyroiditis was a less common cause of subclinical hypothyroidism in CAPD patients. Elevated TSH levels were significantly related to LV systolic dysfunction in CAPD patients. Therefore, further prospective studies will be needed to elucidate the effects of subclinical hypothyroidism on cardiac dysfunction in ESRD patients.

\footnotetext{
References $D_{1}$ Kaptein EM, Quion-Verde H, Chooljian CJ, Tang WW, Friedman PE, Rodriquez HJ, Massry SG: The thyroid in end-stage renal disease. Medicine (Baltimore) 1988;67:187197.

2 Kaptein EM: Thyroid hormone metabolism and thyroid diseases in chronic renal failure. Endocr Rev 1996;17:45-63.

- 3 Wartofsky L, Burman KD: Alterations in thyroid function in patients with systemic illness: the 'euthyroid sick syndrome'. Endocr Rev 1982;3:164-217.
}

Kang/Nam/Yoo/Shin/Kang/Han/Han 
4 Kasper DL, Harrison TR: Harrison's Principles of Internal Medicine, ed 16. New York, McGraw-Hill, 2005.

5 Sawin CT, Chopra D, Azizi F, Mannix JE, Bacharach P: The aging thyroid: increased prevalence of elevated serum thyrotropin levels in the elderly. JAMA 1979;242:247250.

6 Biondi B, Palmieri EA, Lombardi G, Fazio S: Effects of subclinical thyroid dysfunction on the heart. Ann Intern Med 2002;137:904914.

7 Imaizumi M, Akahoshi M, Ichimaru S, Nakashima E, Hida A, Soda M, Usa T, Ashizawa K, Yokoyama N, Maeda R, Nagataki S, Eguchi K: Risk for ischemic heart disease and all-cause mortality in subclinical hypothyroidism. J Clin Endocrinol Metab 2004; $89: 3365-3370$.

8 Goodkin DA, Bragg-Gresham JL, Koenig KG, Wolfe RA, Akiba T, Andreucci VE, Saito A, Rayner HC, Kurokawa K, Port FK, Held PJ, Young EW: Association of comorbid conditions and mortality in hemodialysis patients in Europe, Japan, and the United States: The Dialysis Outcomes and Practice Patterns Study (DOPPS). J Am Soc Nephrol 2003; 14:3270-3277.

-9 Ilercil A, O’Grady MJ, Roman MJ, Paranicas M, Lee ET, Welty TK, Fabsitz RR, Howard BV, Devereux RB: Reference values for echocardiographic measurements in urban and rural populations of differing ethnicity: The Strong Heart Study. J Am Soc Echocardiogr 2001; 14:601-611.
0 Lang RM, Bierig M, Devereux RB, Flachskampf FA, Foster E, Pellikka PA, Picard MH, Roman MJ, Seward J, Shanewise JS, Solomon SD, Spencer KT, Sutton MS, Stewart WJ: Recommendations for chamber quantification: a report from the American Society of Echocardiography's Guidelines and Standards Committee and the Chamber Quantification Writing Group, developed in conjunction with the European Association of Echocardiography, a branch of the European Society of Cardiology. J Am Soc Echocardiogr 2005;18:1440-1463.

11 Hollowell JG, Staehling NW, Flanders WD, Hannon WH, Gunter EW, Spencer CA, Braverman LE: Serum TSH, T(4), and thyroid antibodies in the United States population (1988 to 1994): National Health and Nutrition Examination Survey (NHANES III). J Clin Endocrinol Metab 2002;87:489-499.

12 Tunbridge WM, Evered DC, Hall R, Appleton D, Brewis M, Clark F, Evans JG, Young E, Bird T, Smith PA: The spectrum of thyroid disease in a community: The Whickham Survey. Clin Endocrinol (Oxf) 1977;7:481493.

13 Lo JC, Chertow GM, Go AS, Hsu CY: Increased prevalence of subclinical and clinical hypothyroidism in persons with chronic kidney disease. Kidney Int 2005;67:10471052.

14 Medri G, Carella C, Padmanabhan V, Rossi CM, Amato G, De Santo NG, Beitins IZ, Beck-Peccoz P: Pituitary glycoprotein hormones in chronic renal failure: evidence for an uncontrolled alpha-subunit release. J Endocrinol Invest 1993;16:169-174.

15 Sato K, Okamura K, Yoshinari M, Kuroda T, Ikenoue H, Okazawa K, Mizokami T, Onoyama K, Fujishima M: Reversible primary hypothyroidism and elevated serum iodine level in patients with renal dysfunction. Acta Endocrinol (Copenh) 1992;126:253-259.

16 Robey C, Shreedhar K, Batuman V: Effects of chronic peritoneal dialysis on thyroid function tests. Am J Kidney Dis 1989;13:99-103.
17 Monzani F, Di Bello V, Caraccio N, Bertini A, Giorgi D, Giusti C, Ferrannini E: Effect of levothyroxine on cardiac function and structure in subclinical hypothyroidism: a double blind, placebo-controlled study. J Clin Endocrinol Metab 2001;86:1110-1115.

18 Cooper DS, Halpern R, Wood LC, Levin AA, Ridgway EC: L-thyroxine therapy in subclinical hypothyroidism. a double-blind, placebo-controlled trial. Ann Intern Med 1984; 101:18-24.

19 Biondi B, Fazio S, Palmieri EA, Carella C, Panza N, Cittadini A, Bone F, Lombardi G, Sacca L: Left ventricular diastolic dysfunction in patients with subclinical hypothyroidism. J Clin Endocrinol Metab 1999;84: 2064-2067.

20 Nardi E, Cottone S, Mule G, Palermo A, Cusimano P, Cerasola G: Influence of chronic renal insufficiency on left ventricular diastolic function in hypertensives without left ventricular hypertrophy. J Nephrol 2007;20: 320-328.

21 Zoccali C, Tripepi G, Cutrupi S, Pizzini P, Mallamaci F: Low triiodothyronine: a new facet of inflammation in end-stage renal disease. J Am Soc Nephrol 2005;16:2789-2795.

22 Enia G, Panuccio V, Cutrupi S, Pizzini P, Tripepi G, Mallamaci F, Zoccali C: Subclinical hypothyroidism is linked to micro-inflammation and predicts death in continuous ambulatory peritoneal dialysis. Nephrol Dial Transplant 2007;22:538-544.

23 Bartalena L, Brogioni S, Grasso L, Velluzzi F, Martino E: Relationship of the increased serum interleukin- 6 concentration to changes of thyroid function in nonthyroidal illness. J Endocrinol Invest 1994;17:269-274.

24 Zoccali C, Benedetto F, Mallamaci F, Tripepi G, Cutrupi S, Pizzini P, Malatino LS, Bonanno $G$, Seminara G: Low triiodothyronine and cardiomyopathy in patients with endstage renal disease. J Hypertens 2006;24: 2039-2046. 